\title{
Study for a Wall-Climbing Robot Magnetic Attraction Force of An Electronically Controlled Permanent Magnet
}

\author{
Xin Chen ${ }^{1}$, Wuwei Feng ${ }^{1,2}$, Yulian Zhang ${ }^{1,2 *}$, Minglei $\mathrm{Li}^{1}$, Shifei $\mathrm{Wu}^{3}$ \\ ${ }^{1}$ School of Marine Engineer Equipment, Zhejiang Ocean University, Zhoushan, 316022, China \\ ${ }^{2}$ Dong hai Institute of science and technology, Zhejiang Ocean University, Zhoushan, 316000, China \\ ${ }^{3}$ Zhoushan sewage treatment Co., Ltd, Zhoushan, 316022, China \\ *Corresponding Author.
}

\begin{abstract}
With the advancement in science and technology, a wall-climbing robot attached to the ship's outer surface is increasingly replacing humans in the rust removal. The magnetic force is not just the adsorption force but also the moving resistance force, which is currently the technological bottleneck in wall-climbing robotics based on magnetic adsorption. This paper proposes a novel wall-climbing robot based on electrically controlled permanent magnet technology to solve this problem. An electrically controlled permanent magnetic wall-climbing robot is proposed to realize the function of magnetization and demagnetization by changing the pulse current. The results of the experiments reveal that the magnetizing force is adequately adsorbed on the ship's outer surface. The magnetic attraction force is close to $0 \mathrm{~N}$ during demagnetization, meaning that the system is fully unloaded, as predicted by the theoretical analysis.
\end{abstract}

Keywords: Wall-climbing robot, electronically controlled permanent magnet, magnetic pole unit; magnetic attraction force, finite element analysis

\section{Introduction}

Ship surface rust removal is the most common maintenance issue facing the shipbuilding industry and the ship repair industry $[1,2]$. Once the coating on a ship's outer surface is damaged, any steel exposed to the air or immersed in water is easily corroded. For ships immersed in seawater for a long time, the corrosion is more serious. In general, ship rust removal and cleaning are preliminary steps to paint [3,4]. After rust removal, spray painting can be carried out to protect a ship's walls from corrosion to extend the service life of the ship. However, at present, most shipyards still use manual derusting, which not only endangers the health of workers but also pollutes the environment. Automated machinery has gradually replaced manual labor in high-risk jobs as science and technology have progressed, with the use of a wall-climbing robot being a notable example. The wall-climbing robot is a unique type of robot that is typically used on the ship's exterior. It is important to ensure that the robot can be stably adsorbed on the wall in a static position and that the robot can securely adhere to the wall while it "walks." Therefore, the magnetic attraction force is the most important feature for a wall-climbing robot, which is why most researchers have studied robots with reliable adsorption forces [5].

Adsorption methods can be categorized as negative pressure adsorption, micro- needle adsorption, grip adsorption, binder adsorption, magnetic adsorption, etc. Adsorption-type wall-climbing robot development has yielded a variety of findings, and the application scenarios are getting more extensive, so more people are paying attention to their work[6,7]. The United States Helical Robotics and other companies developed a series of robots for wall crawling, such as HR-MP20, using permanent magnet adsorption, using wheeled mobile [8]. Chen et al. suggested a new form of multi-vacuum sucker wall climbing robot. The robot can walk vertically on a variety of materials [9]. Yu et al. developed a new legged gecko robot with 16 active degrees of freedom and 12 passive degrees of freedom that could climb omni-directional surfaces with dry adhesive material using a diagonal gait motion.[10]. A new negative

ISSN: 0010-8189

(C) CONVERTER 2020

www.converter-magazine.info 
pressure adsorption mechanism is integrated into the design of a climbing robot. This mechanism creates and maintains negative pressure and adsorption force by using the gravitational force of air. [11-13]. Mao et al. developed a permanent magnetic adsorption unit that has a significant adsorption capacity. [14]. Huang et al. proposed a novel electromagnetic adsorption-based wall-climbing robot. To achieve the unity of adsorption and mobility, electromagnets fixed in synchronous belts go into and out of work in turn. Park and Seo proposed a new type of wall-climbing robot that moves like a gorilla [15]. It consists of a DC drive motor, an adsorption vacuum pump, and a microcontroller for machine control. On vertical and horizontal flat surfaces, the robot's efficiency was done previously $[16,17]$. An adsorption device with a flexible skirt edge was presented by Hefei University. With a maximum load of $0.5 \mathrm{~kg}$, the robot could climb the wall surface from 0 to 360 degrees.

As previously mentioned, when compared to other common climbing robots, such as vacuum adsorption and negative pressure adsorption robots, the permanent magnet adsorption method has great adaptability to the wall surface, and the adsorption force is far greater than vacuum adsorption. Meanwhile, the biped adsorption type is focused on animal, human behavior, and development. This approach is relatively difficult to control, and the function is relatively poor. The main challenge is the inability to have the required industrial application direction. [18]. Compared with the electromagnetic adsorption device, the permanent magnet adsorption device has a smaller weight and volume, does not need a power supply and cooling equipment, and has no safety hazards due to accidental power failure and loss of adsorption [19,20]. However, permanent magnet adsorption is unable to overcome the conflict between adsorption flexibility and stability. The motion form and adsorption methods are the two major themes of the wall-climbing robot. And the two are at odds: the more flexible the movement, the lower the adsorption force should be. This paper proposes a wall-climbing robot based on electrically controlled permanent magnet technology that can magnetize and demagnetize by altering the pulse current. Electrically controlled permanent magnet technology addresses the contradiction between the maneuverability and the adsorption force of the wall-climbing robot.

The below is a description of the paper's structure: The magnetic circuit structure and operation of the electronically controlled permanent magnetic pole unit was discussed in Section 2. We also calculate the magnetic circuit and magnetic attraction force of the magnetic pole unit with the Maxwell equation. A finite element analysis is presented in Section 3 to simulate and verify the magnetic attraction force during magnetization and demagnetization. Finally, conclusions are outlined.

\section{Magnetic circuit analysis and calculation of the magnetic pole unit}

\subsection{Magnetic circuit structure of the magnetic pole unit}

The magnetic pole unit is composed of a magnetic yoke, magnetic pole block, main magnet, reversible magnet and excitation coil. Fig. 1 and Fig 2 represent a physical diagram and a 3D model of the magnetic pole unit, respectively. The outermost frame is the yoke, and the internal structure is divided into upper and lower parts. The main magnet is the one with the smaller volume next to the yoke, the larger magnet is the pole block, and the magnet directly below the pole block is a reversible magnet that is surrounded by an excitation coil, which is made of wound copper wire. To increase the strength and stiffness of the magnetic pole unit and fix the excitation coil and reversible magnet, they are sealed and insulated to prevent liquid from entering and promoting coil leakage. To fill the internal gap of the pole unit, epoxy resin is used around the excitation coil [21]. 


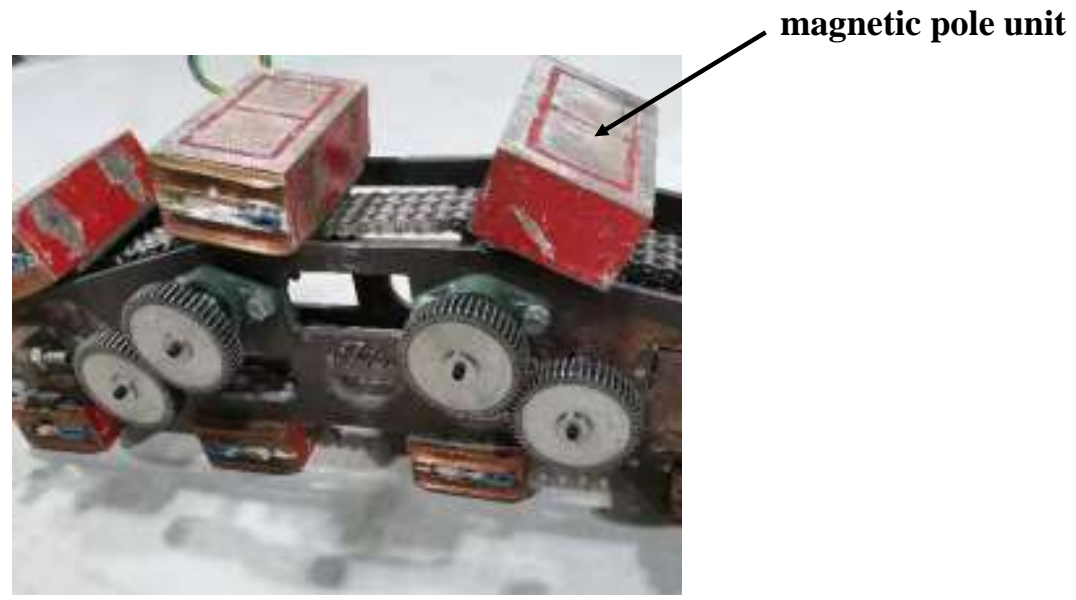

Fig 1: The physical diagram of magnetic pole unit

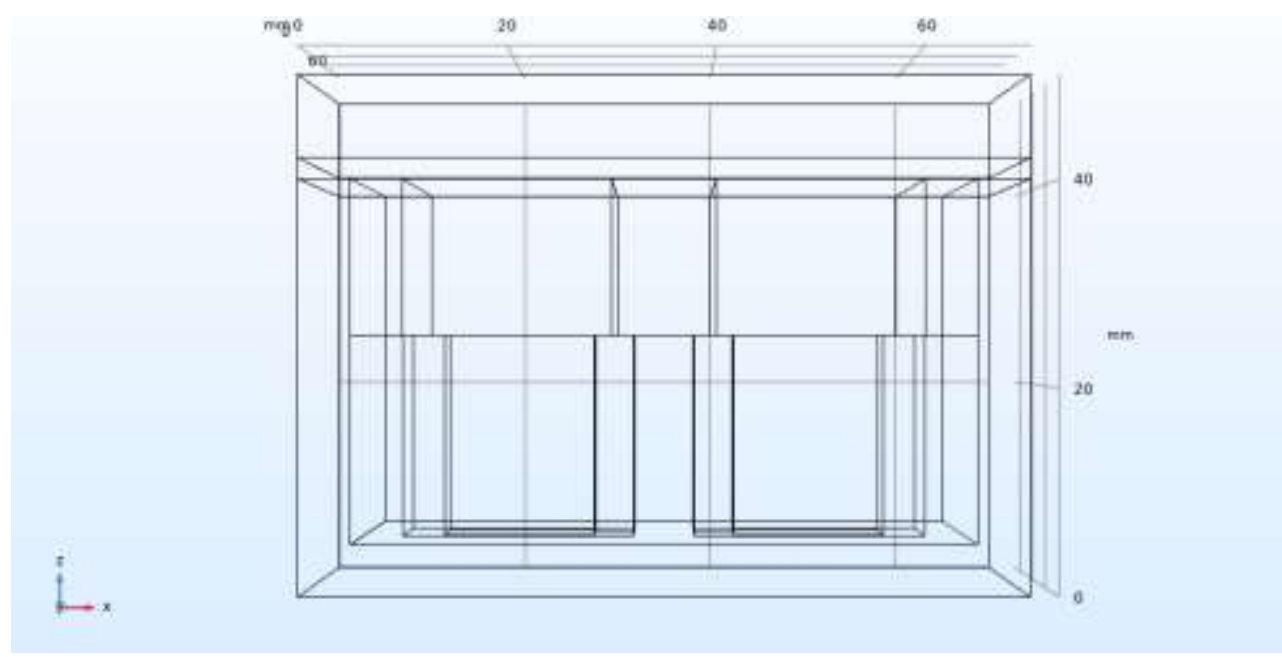

Fig. 2: The 3D model of the magnetic pole unit

2.2 Working principle of the magnetic pole unit

When the magnetic pole unit is magnetized, a positive pulse current is instantaneously applied to the excitation coil to magnetize the reversible magnet. The direction of the magnetic pole after the magnetization of the reversible magnet is shown in Fig. 3(a). The magnetic fields are superimposed on each other, and the magnetic lines of force pass through the magnetically conductive workpiece to form a closed magnetic circuit. Most of the magnetic field lines pass through the magnetic pole block, air gap, magnetic workpiece, and air gap, magnetic pole block, reversible magnet, magnetic yoke and reversible magnet successively to form a closed circuit, that is, the main magnetic circuit. There are a few magnetic field lines that pass through the magnetic pole block, air gap, magnetic workpiece, and air gap in turn to form a closed loop, which is the secondary magnetic circuit. As a result, between the magnetic pole unit and the magnetic workpiece, a magnetic attraction force is generated, which is manifested as a magnetizing state.

When the magnetic pole unit is demagnetized, a reverse pulse current is instantaneously applied to the excitation coil to magnetize the reversible magnet. The direction of the magnetic pole of the reversible magnet is shown in Fig. 3 (b). The direction of the magnetic pole of the reversible magnet is opposite to that of the magnetizing magnet. The magnetic poles of the magnet and the reversible magnet are opposite magnetic poles, and most of the distribution for the magnetic lines of force forms a closed loop inside the magnetic pole unit. Therefore, the magnetic attraction force between the magnetic pole unit and the magnetic conductive workpiece is minimal, implying that the demagnetization state is the external performance.

ISSN: 0010-8189 


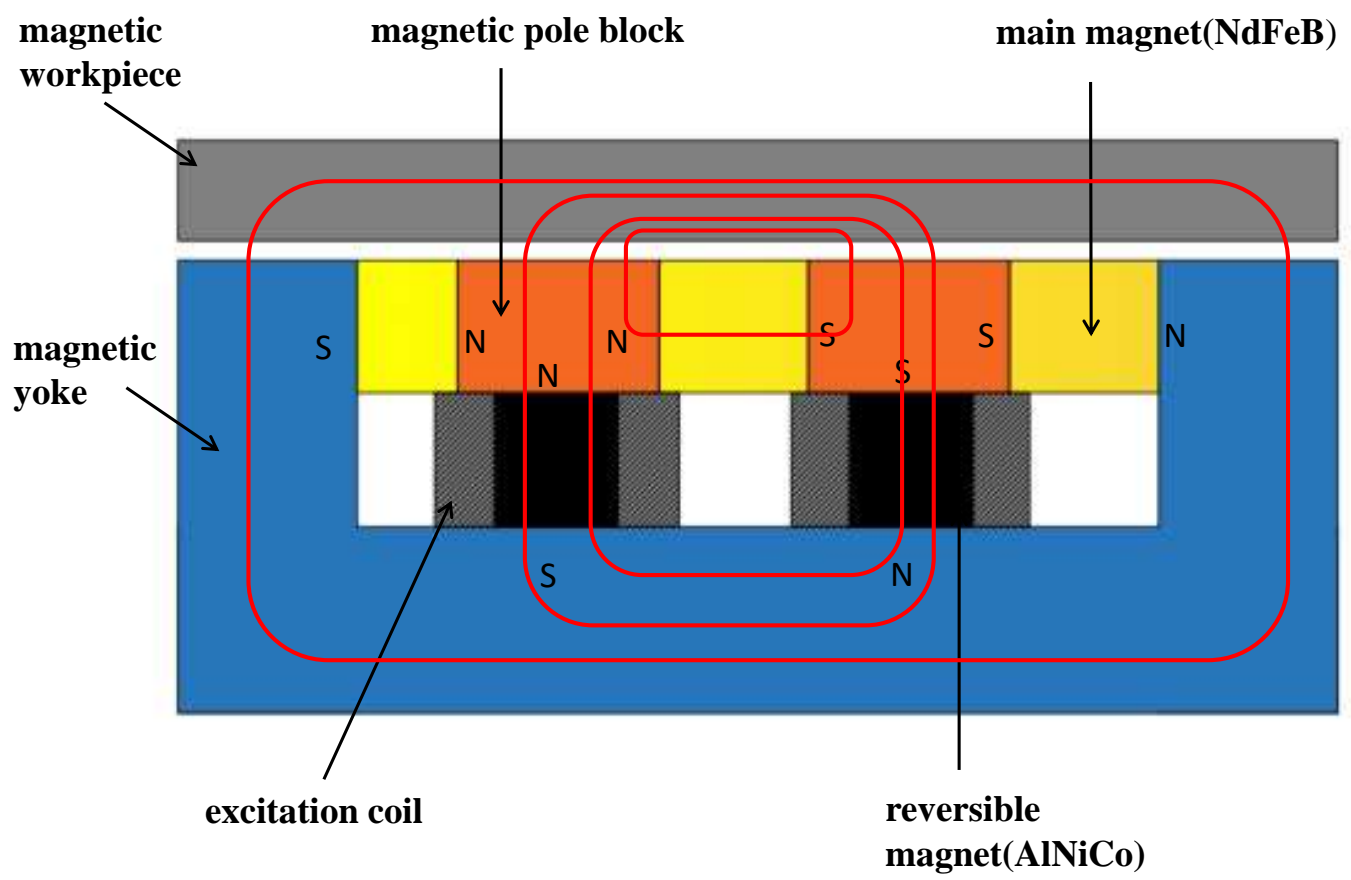

(a)

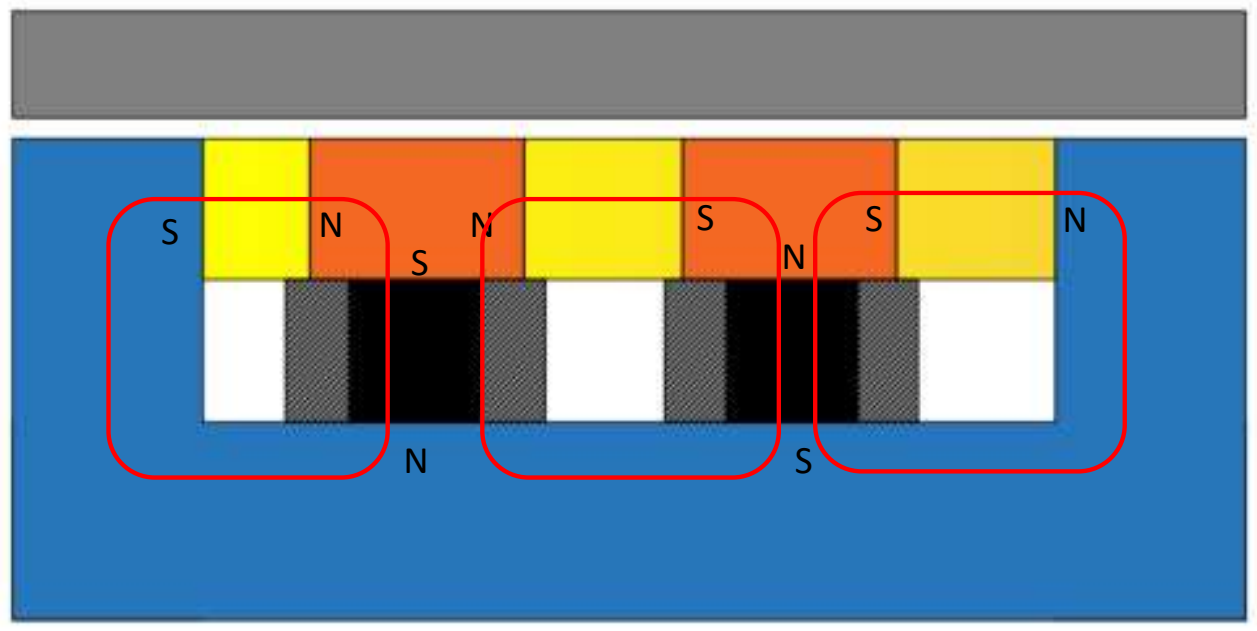

(b)

Fig 3: Distribution of the magnetic lines of electrically controlled permanent magnet (a) Magnetization state (b) Demagnetization state

2.3 Magnetic circuit calculation of the magnetic pole unit

In general, the magnetic circuit consists of five parts: the permanent magnet material, an excitation coil, the soft magnetic material, the assembly clearance and the working air gap. Assume the permanent magnet material's internal magnetic field strength is $\mathrm{H}_{\mathrm{m}}$ and its length is $\mathrm{L}_{\mathrm{m}}$. There are $\mathrm{k}$ excitation coils, the number of turns of the $\mathrm{i}$-th winding is $N_{i}$ and the current is $I_{i}$. There are $m$ segments of soft magnetic materials, the length of the $i$-th segment is $L_{i}$ and the internal magnetic field intensity is $H_{i}$. There are $n$ assembly gaps, with $L_{j}$ being the length of the $j$-th

ISSN: 0010-8189

(C) CONVERTER 2020

www.converter-magazine.info 
segment, $\mathrm{H}_{\mathrm{j}}$ being the magnetic field intensity in the assembly gap, and $\mathrm{L}_{\mathrm{g}}$ being the length of the working air gap and $\mathrm{H}_{\mathrm{g}}$ being the magnetic field intensity in the working air gap.

The calculation formula for the magnetic circuit in a magnetic pole unit can be derived via Kirchhoff's second law of magnetic circuits:

$$
\begin{gathered}
\sum_{\mathrm{i}=1}^{\mathrm{m}} \mathrm{H}_{\mathrm{i}} \mathrm{L}_{\mathrm{i}}+\sum_{\mathrm{j}=1}^{\mathrm{n}} \mathrm{H}_{\mathrm{j}} \mathrm{L}_{\mathrm{i}}+\mathrm{H}_{\mathrm{g}} \mathrm{L}_{\mathrm{g}}=0.4 \Pi \sum_{\mathrm{i}=1}^{\mathrm{k}} \mathrm{N}_{\mathrm{i}} \mathrm{L}_{\mathrm{i}} \\
\sum_{\mathrm{i}=1}^{\mathrm{m}} \mathrm{H}_{\mathrm{i}} \mathrm{L}_{\mathrm{i}}+\sum_{\mathrm{j}=1}^{\mathrm{n}} \mathrm{H}_{\mathrm{j}} \mathrm{L}_{\mathrm{i}}+\mathrm{H}_{\mathrm{g}} \mathrm{L}_{\mathrm{g}}=\mathrm{H}_{\mathrm{m}} \mathrm{L}_{\mathrm{m}} \\
\sum_{\mathrm{i}=1}^{\mathrm{m}} \mathrm{H}_{\mathrm{i}} \mathrm{L}_{\mathrm{i}}+\sum_{\mathrm{j}=1}^{\mathrm{n}} \mathrm{H}_{\mathrm{j}} \mathrm{L}_{\mathrm{i}}+\mathrm{H}_{\mathrm{g}} \mathrm{L}_{\mathrm{g}}=0.4 \Pi \sum_{\mathrm{i}=1}^{\mathrm{k}} \mathrm{N}_{\mathrm{i}} \mathrm{L}_{\mathrm{i}}+\mathrm{H}_{\mathrm{m}} \mathrm{L}_{\mathrm{m}}
\end{gathered}
$$

To calculate the magnetized AlNiCo permanent magnet material for the excitation coil in the electronically controlled permanent magnet pole unit, since there is no working gap, the assembly gap can be ignored. Formula 3 can be used to obtain the magnetic circuit calculation formula for the magnetized AlNiCo permanent magnet material as follows:

$$
0=0.4 \Pi \sum_{\mathrm{i}=1}^{\mathrm{k}} \mathrm{N}_{\mathrm{i}} \mathrm{L}_{\mathrm{i}}+\mathrm{H}_{\mathrm{m}} \mathrm{L}_{\mathrm{m}}
$$

The magnetic circuit of an electronically controlled permanent magnet pole unit is equivalent to the permanent magnetic circuit when magnetized and demagnetized, and the magnetic circuit can be calculated using formula 2 .

2.4 Magnetic attraction force calculation of the magnetic pole unit

Since the gap between an electronically controlled permanent magnetic chuck and the magnetizing workpiece is so small as it performs, it is presumed that the air gap magnetic induction is uniformly distributed. [22]. According to Maxwell's differential equation, the magnetic attraction force calculation formula for the electronic control of a permanent magnet pole unit can be derived as follows:

$$
\mathrm{F}=10^{8} \times\left(\frac{\mathrm{Bg}_{\mathrm{g}}}{4965}\right)^{2} \mathrm{~A}_{\mathrm{g}}=10^{9} \times\left(\frac{\Phi_{\mathrm{g}}}{4965}\right)^{2} \frac{1}{\mathrm{Ag}_{\mathrm{g}}}
$$

Where $\mathrm{F}$ denotes the magnetic attraction force, $\mathrm{B}_{\mathrm{g}}$ denotes the magnetic induction intensity, $\mathrm{A}_{\mathrm{g}}$ denotes the contact area and $\Phi_{\mathrm{g}}$ denotes the air gap flux density.

The magnetic induction intensity $\mathrm{B}_{\mathrm{g}}$ and the contact area $\mathrm{A}_{\mathrm{g}}$ between the magnetic pole unit and the magnetic workpiece determine the magnetic attraction force. The magnetic attraction force is unaffected by the contact area $A_{g}$, the structural parameters of the magnetic pole, or the number of excitation coils when the magnetic pole unit and the magnetic conducting workpiece are determined. The working air gap magnetic induction intensity $\mathrm{B}_{\mathrm{g}}$ determines the magnetic attraction force between them. The magnetic induction intensity $\mathrm{B}_{\mathrm{g} 1}$ produced by the main magnet and the magnetic induction intensity $B_{\mathrm{g} 2}$ produced by the reversible magnet are superimposed on the working air gap magnetic induction intensity $\mathrm{B}_{\mathrm{g}}$ between the magnetic pole system and the workpiece. According to the working principle of the magnetic pole unit, the magnetic intensity $\mathrm{B}_{\mathrm{g} 1}$ produced by the main permanent magnet in the magnetic pole unit does not change. A pulse current is applied to the excitation coil to control the magnetic induction intensity $\mathrm{B}_{\mathrm{g} 2}$ produced by the magnetized reversible magnet and to control the working magnetic induction intensity $\mathrm{B}_{\mathrm{g}}$.

\section{COMSOL finite element analysis}

ISSN: 0010-8189

(C) CONVERTER 2020 
COMSOL Multiphysics is large-scale advanced numerical simulation software that's used in a variety of scientific and engineering calculations[23]. In the simulation of various physical processes in science and engineering fields, COMSOL generates highly accurate numerical simulations with excellent computational performance and multi-field bidirectional direct coupling analysis capabilities. At present, it has been widely used in electromagnetics, structural mechanics, acoustics and other fields. In this paper, during magnetization and demagnetization, the AC/DC module of the simulation software is used to verify the magnitude of the magnetic attraction force between the magnetic pole unit and the magnetic workpiece. Fig. 4 represents the sequence in which the major steps are performed.

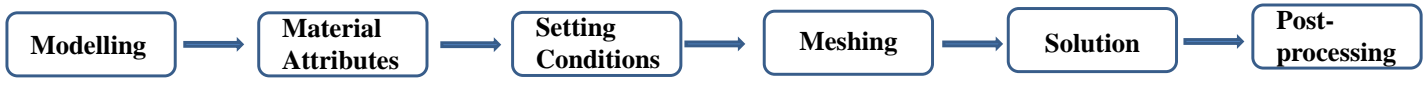

Fig 4: Simulation flow chart

In this paper, we verify two cases of magnetic attraction force between the magnetic pole unit and the magnetic workpiece: one in which the magnetic attraction force between the magnetic pole unit and the magnetic workpiece can exceed $800 \mathrm{~N}$ under magnetization conditions, and another in which the magnetic attraction force between the magnetic pole unit and the magnetic workpiece is close to $0 \mathrm{~N}$ under demagnetization conditions [24].

\subsection{Modelling}

The model of the magnetic pole unit and the magnetic conductive workpiece is established based on the magnetic circuit structure of the magnetic pole unit in Chapter 2. (see Fig 5).

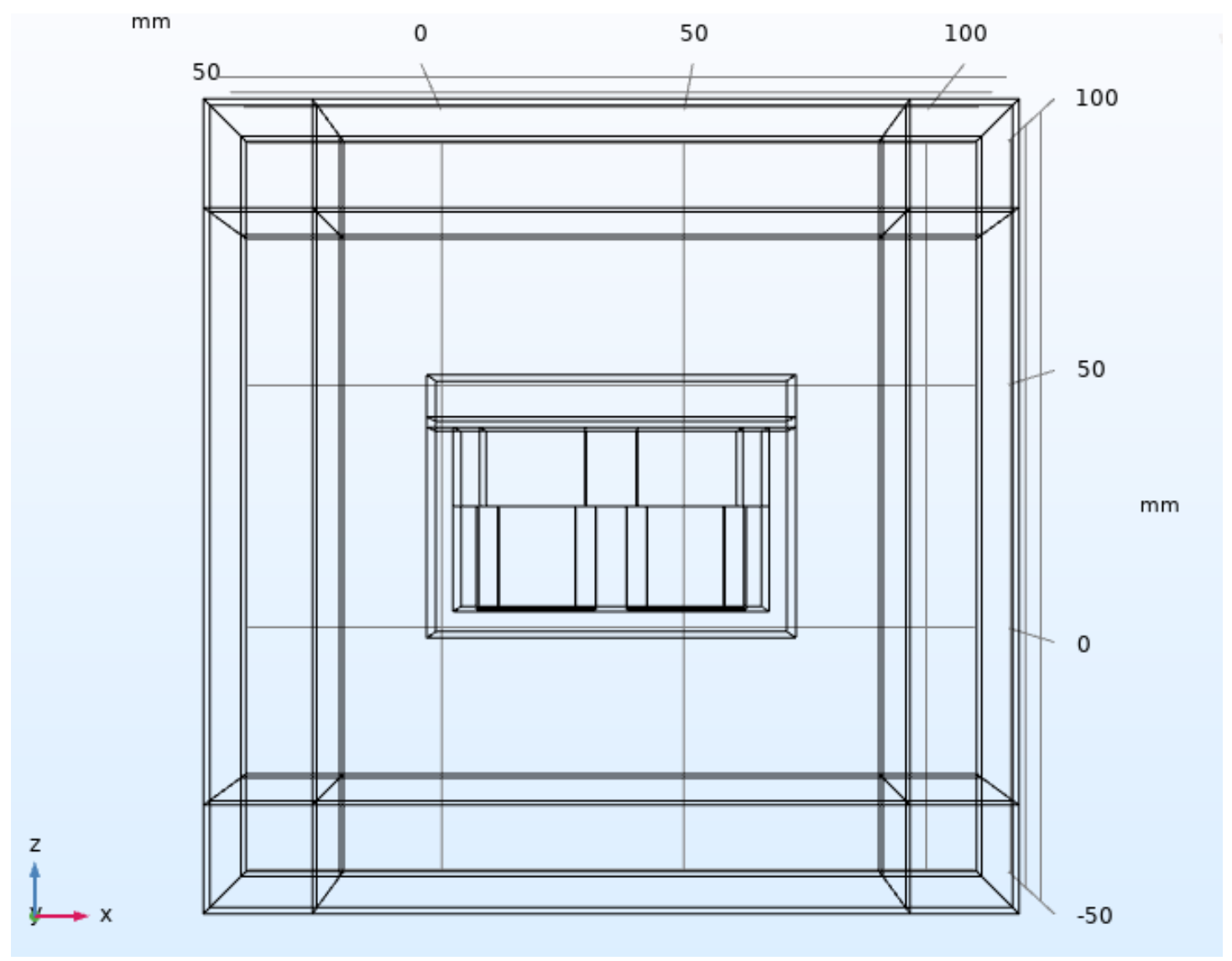

Fig 5: The model of the magnetic pole unit and the magnetic conductive workpiece 


\subsection{Material Attributes}

Electromagnetic field analysis involves materials such as magnetic yoke, the magnetic pole block, main magnet $(\mathrm{NdFeB})$, reversible magnet $(\mathrm{AlNiCo})$ and excitation coil, magnetic workpiece, air, its parameters are shown in Table 1. In the simulation process, H-B corresponding values and curves of AlNiCo are shown in the Table 2 and Fig. 6 respectively.

Table 1 Material parameters

\begin{tabular}{|c|c|}
\hline Material & Properties \\
\hline main magnet(NdFeB) & $B_{r 1}=1.281 T$ \\
& $H_{c 1}=483 \mathrm{kA} / \mathrm{m}$ \\
& $\mu_{1}=1.0875$ \\
\hline reversible magnet(AlNiCo) & $B_{r 2}=1.334 T$ \\
& $H_{c 2}=61.6 \mathrm{kA} / \mathrm{m}$ \\
\hline magnetic pole block & $\mu_{2}=2000$ \\
\hline magnetic workpiece & $\mu_{3}=1000$ \\
\hline magnetic yoke & $\mu_{4}=400$ \\
\hline air & $\mu_{5}=1$ \\
\hline excitation coil & $\mathrm{N}=95, \mathrm{I}=25 \mathrm{~A}$ \\
\hline
\end{tabular}

Table $2 \mathrm{H}-\mathrm{B}$ corresponding value of demagnetization curve of AlNiCo

\begin{tabular}{|c|c|c|c|c|c|}
\hline $\mathrm{H}(\mathrm{Oe})$ & $\mathrm{B}(\mathrm{T})$ & $\mathrm{H}(\mathrm{Oe})$ & $\mathrm{B}(\mathrm{T})$ & $\mathrm{H}(\mathrm{Oe})$ & $\mathrm{B}(\mathrm{T})$ \\
\hline 55703.9 & 1.32588 & 11936.6 & 1.21294 & 3978.9 & 0.84376 \\
\hline 51725.1 & 1.32176 & 9946.2 & 1.17176 & 3481.5 & 0.74694 \\
\hline 43767.4 & 1.31294 & 7957.7 & 1.119059 & 2984.1 & 0.64941 \\
\hline 35810.0 & 1.30235 & 6963.0 & 1.06766 & 2486.8 & 0.55353 \\
\hline 27852.0 & 1.29117 & 5967.4 & 1.01294 & 1989.4 & 0.48894 \\
\hline 23873.1 & 1.281176 & 5470.9 & 0.98106 & 1492.1 & 0.38471 \\
\hline 19894.3 & 1.26588 & 4973.6 & 0.94612 & 994.7 & 0.22176 \\
\hline 15915.4 & 1.24647 & 4476.2 & 0.88353 & 497.4 & 0.112 \\
\hline
\end{tabular}


$H B(t)$

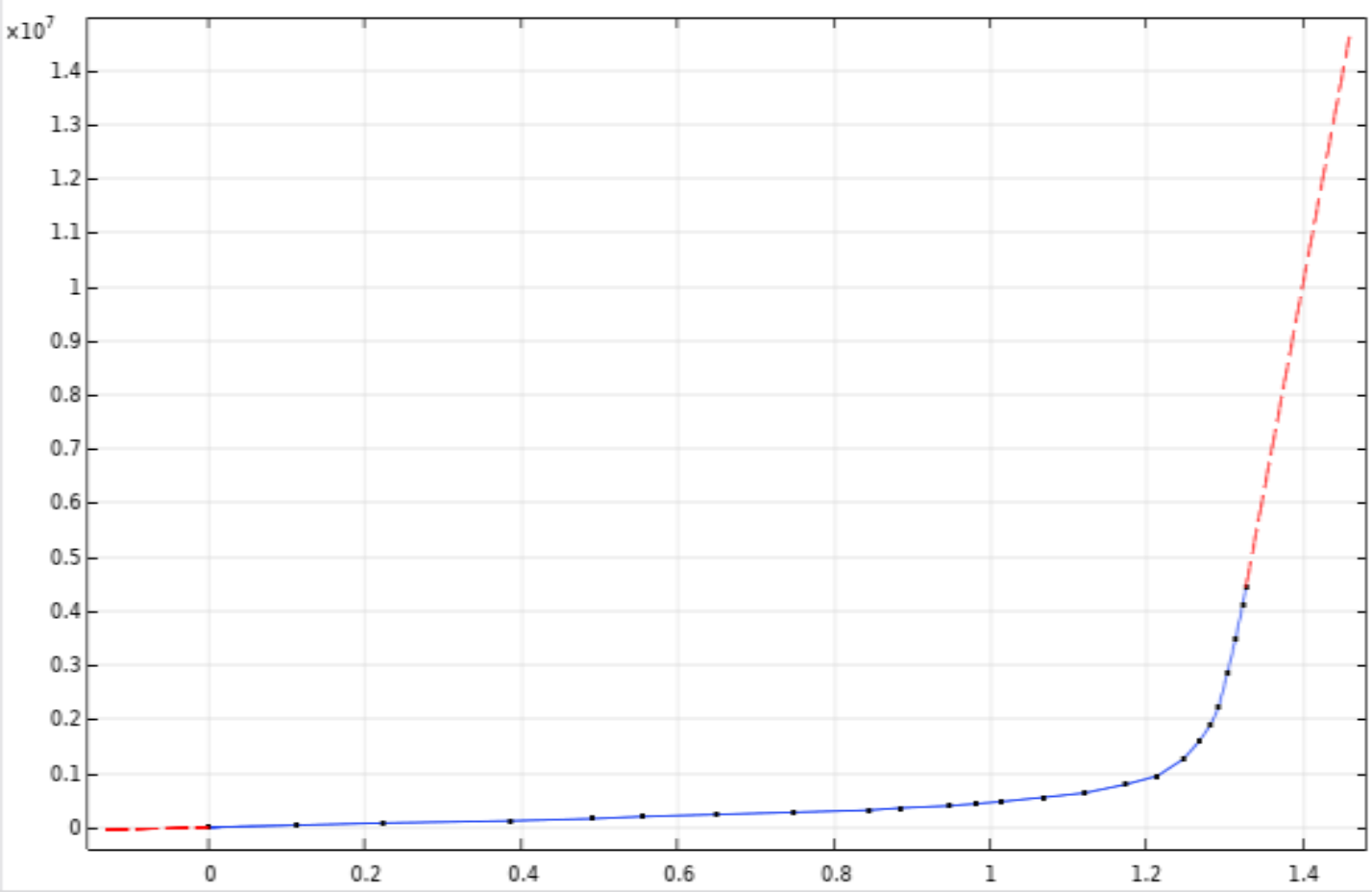

Fig 6: H-B curve

3.3 Setting conditions

Boundary conditions are set for electromagnetic field interfaces and impulse current excitation functions are applied as shown in Table 3 and Fig. 7 respectively.

Table 3 Boundary conditions of magnetic field interface

\begin{tabular}{|c|c|c|}
\hline Boundary conditions & Equation & Constitutive relation \\
\hline Ampere's Law(field 1) & $\begin{array}{c}\nabla \times \mathrm{H}=\mathrm{J} \\
\mathrm{B}=\nabla \times \mathrm{A} \\
\mathrm{E}=-\frac{\partial_{\mathrm{A}}}{\partial_{\mathrm{t}}} \\
\mathrm{J}=\sigma \mathrm{E}\end{array}$ & $\mathrm{B}=\mu_{0} \mu_{\mathrm{r}} \mathrm{H}$ \\
\hline Ampere's Law(field 2) & $\begin{array}{c}\nabla \times \mathrm{H}=\mathrm{J} \\
\mathrm{B}=\nabla \times \mathrm{A} \\
\mathrm{E}=-\frac{\partial_{\mathrm{A}}}{\partial_{\mathrm{t}}} \\
\mathrm{J}=\sigma \mathrm{E}\end{array}$ & $\mathrm{B}=\mu_{0} \mu_{\mathrm{r}} \mathrm{H}+\mathrm{B}_{\mathrm{r}}$ \\
\hline Ampere's Law(field 3) & $\begin{array}{c}\nabla \times \mathrm{H}=\mathrm{J} \\
\mathrm{B}=\nabla \times \mathrm{A} \\
\mathrm{E}=-\frac{\partial_{\mathrm{A}}}{\partial_{\mathrm{t}}} \\
\mathrm{J}=\sigma \mathrm{E}\end{array}$ & $\mathrm{B}=\mu_{0} \mu_{\mathrm{r}} \mathrm{H}+\mathrm{B}_{\mathrm{r}}$ \\
\hline Ampere's Law(field 4) & $\begin{array}{c}\nabla \times \mathrm{H}=\mathrm{J} \\
\mathrm{B}=\nabla \times \mathrm{A} \\
\mathrm{E}=-\frac{\partial_{\mathrm{A}}}{\partial_{\mathrm{t}}} \\
\mathrm{J}=\sigma \mathrm{E}\end{array}$ & $H=f(|B|) \frac{B}{|B|}$ \\
\hline
\end{tabular}

ISSN: 0010-8189 


\begin{tabular}{|c|c|c|}
\hline Magnetic Insulation & $\mathrm{n} \times \mathrm{A}=0$ & \\
\hline Coil Excitation & $\mathrm{J}_{\mathrm{e}}=\frac{\mathrm{NI}_{\text {coil }}}{\mathrm{A}} \mathrm{e}_{\text {coil }}$ & $\mathrm{B}=\mu_{0} \mu_{\mathrm{r}} \mathrm{H}$ \\
\hline
\end{tabular}

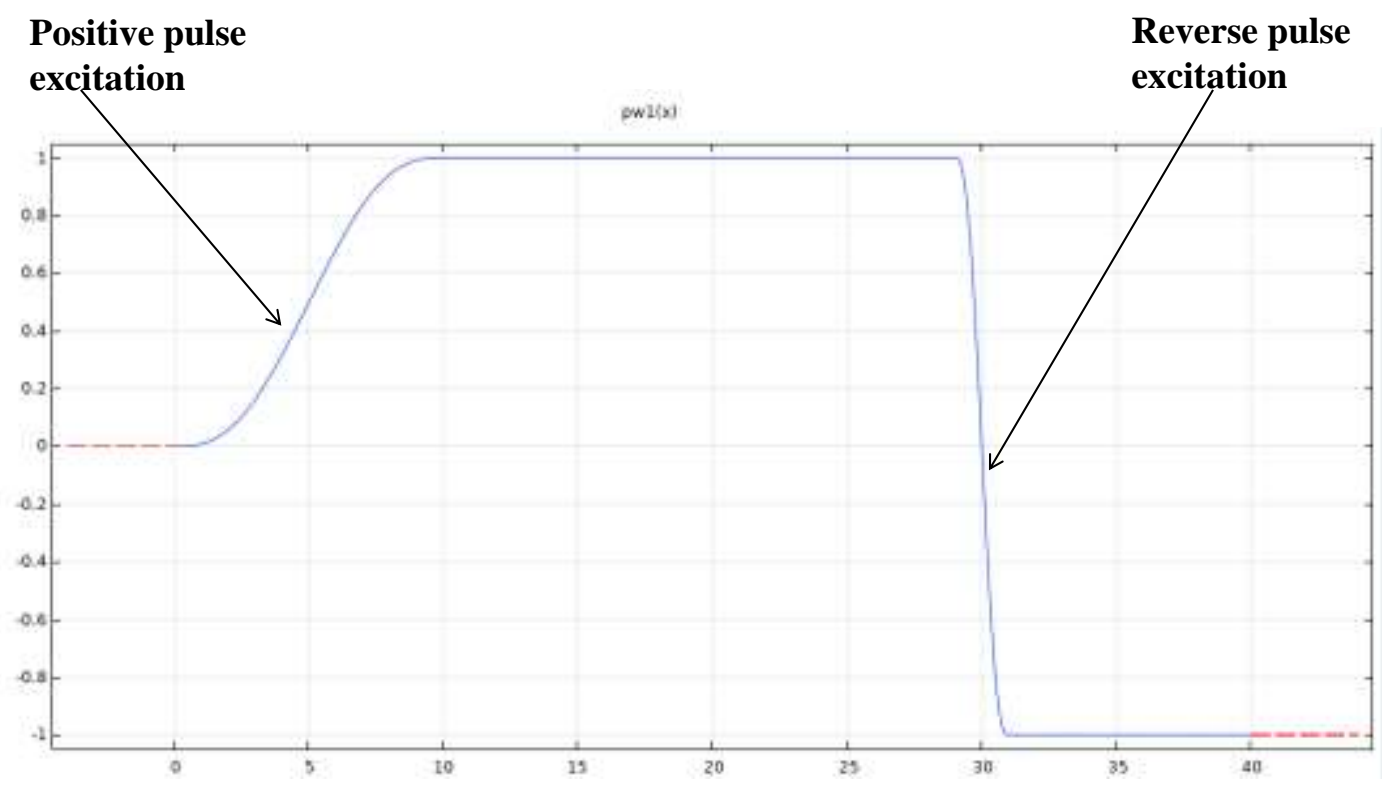

Fig 7: Impulse current excitation function

\subsection{Meshing}

The meshing of geometric model directly determines the calculation of the problem, including the solving time of the model, the amount of memory needed to calculate the problem and the precision of the solution. This article uses automatic meshing, as shown in Fig 8.

ISSN: 0010-8189 


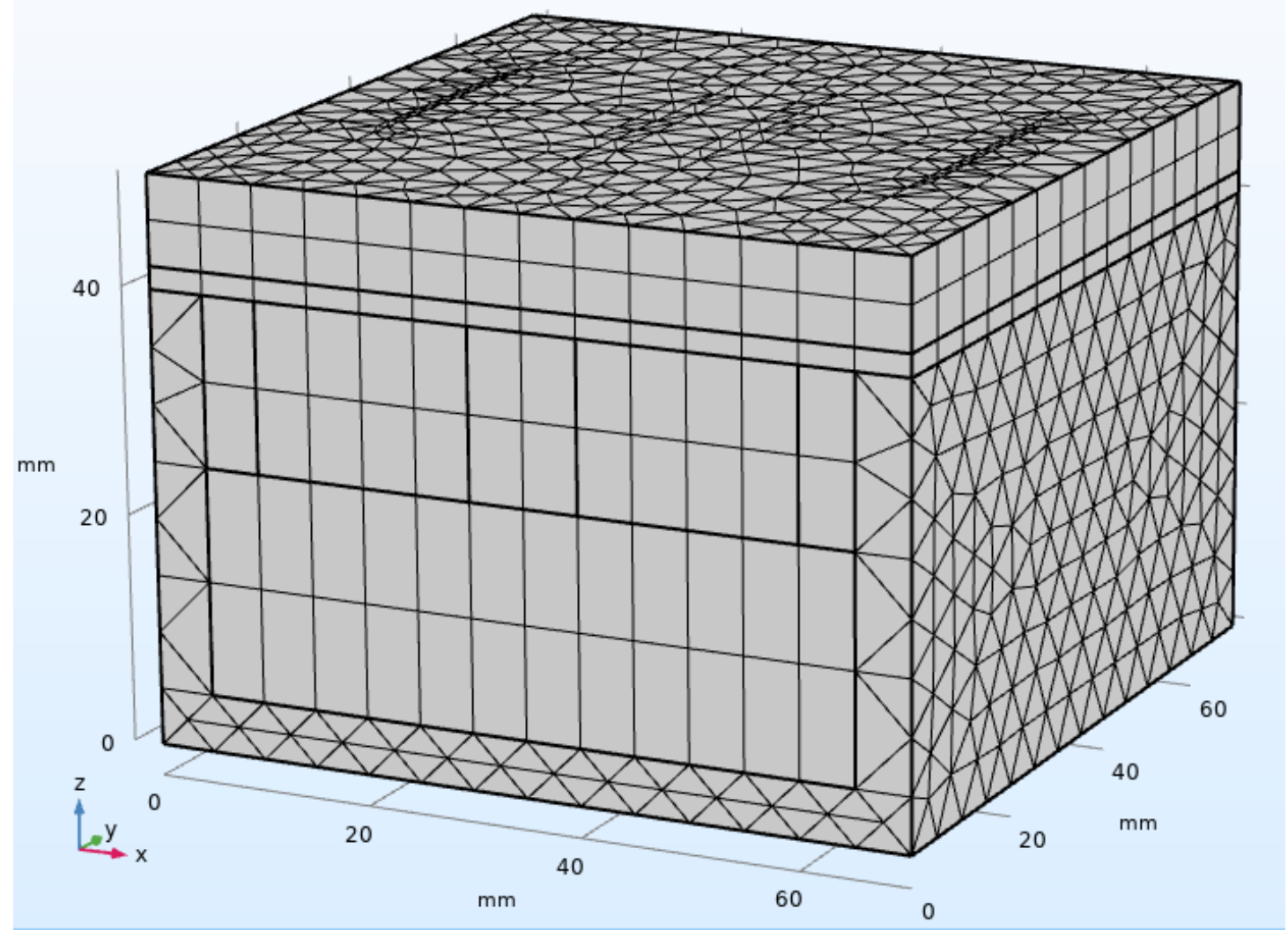

Fig 8: Meshing diagram

\subsection{Solution}

COMSOL Multiphysics is used to form a discrete system of linear algebraic equations based on a series of interrelated small units through discrete means and then solves the equations to obtain a solution for the unit node. In this paper, a stationary solver, time-dependent solver and stationary segregated solver are used to solve the problem. The iterative solver adopts a fine iterative strategy. In solving the nonlinear equation, the iterative solution is obtained, and the solution that meets the precision requirement is finally obtained. The segregated solver is mainly used to solve the weak coupling problem. The physical fields are solved in order, and then the coupling iteration is carried out repeatedly until the accuracy requirements are met.

\subsection{Post-processing}

The magnetic attraction force between the magnetic pole unit and the magnetic conductive workpiece is $800 \mathrm{~N}$ under magnetization, as seen in Fig. 9, satisfying the adsorption requirements. In the case of demagnetization, the magnetic attraction force between the magnetic pole unit and the magnetic workpiece is close to $0 \mathrm{~N}$, which meets the unloading requirements. The magnetic force line distribution on the magnetic workpiece is rather uniform, as seen in Fig. 10, implying that the magnetic suction distribution is relatively uniform. 
CONVERTER MAGAZINE

Volume 2021, No. 2

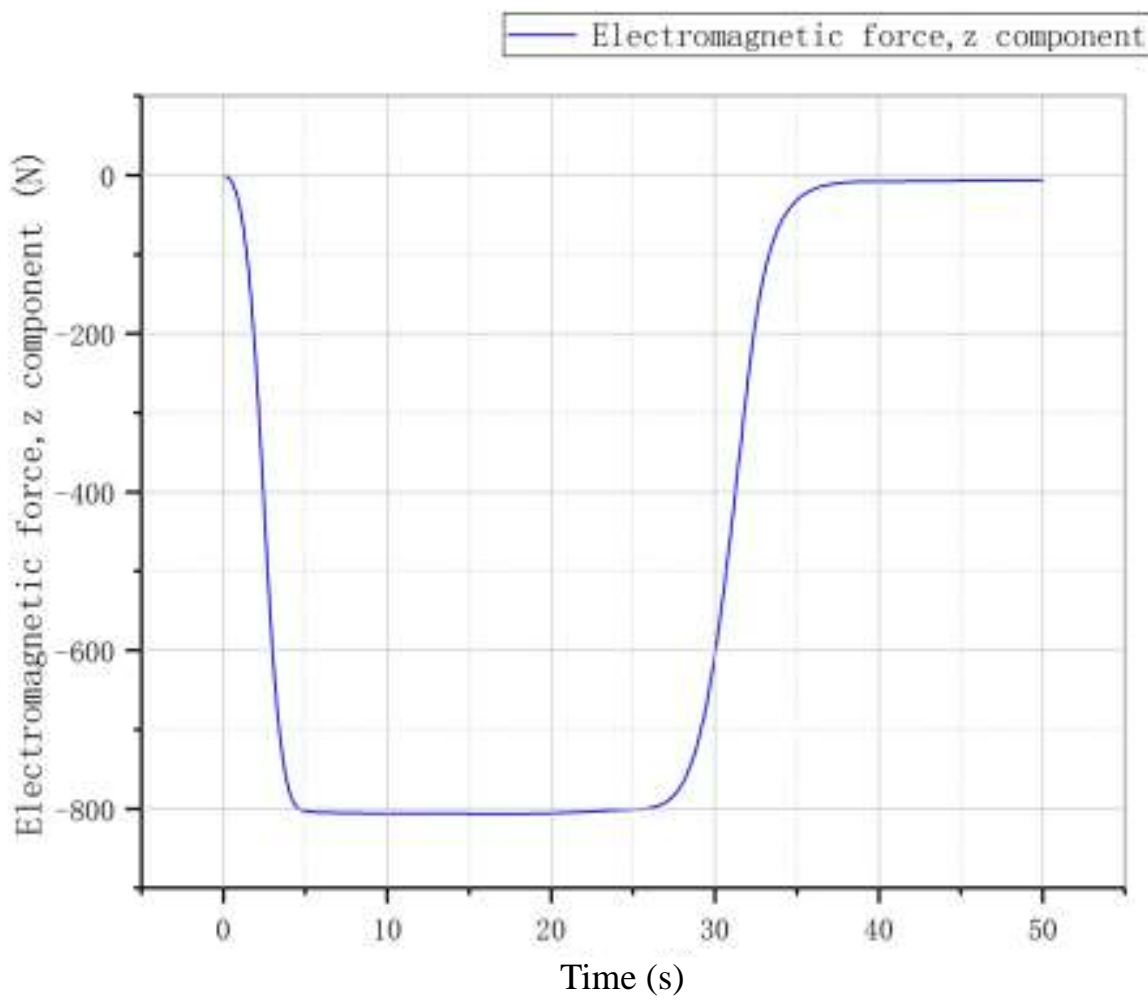

Fig 9: Magnetic attraction force between magnetic pole element and magnetic workpiece

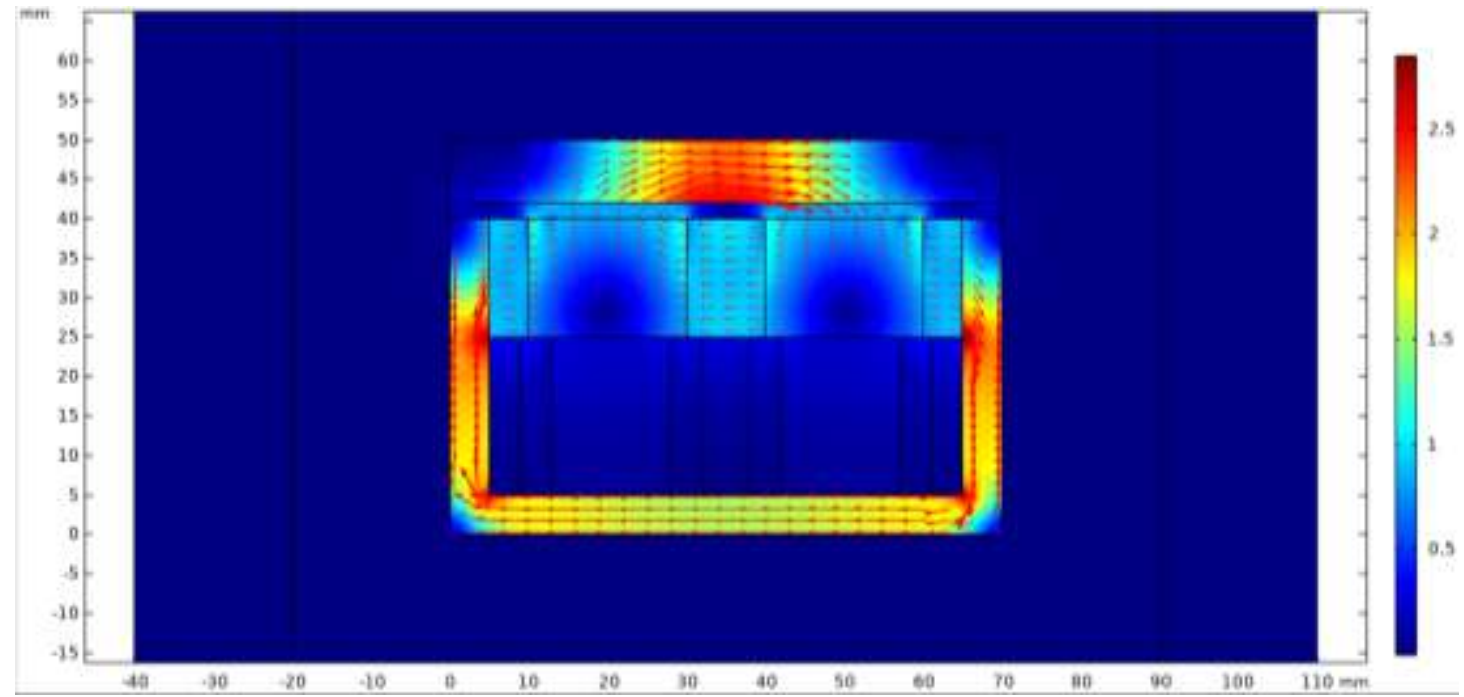

(a)

ISSN: 0010-8189

(C) CONVERTER 2020 


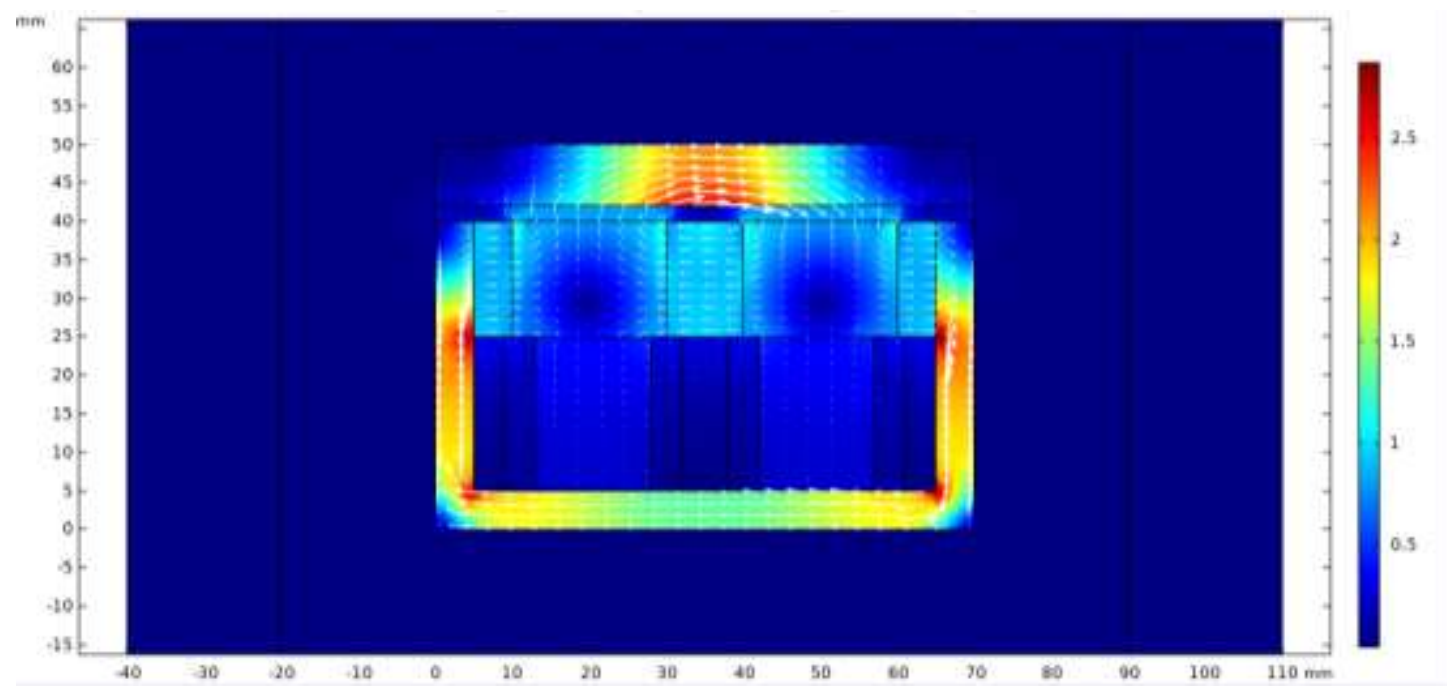

(b)

Fig 10: The distribution of magnetic force line on the magnetic workpiece (a) Magnetization state (b) Demagnetization state

\section{Conclusions}

In this paper, a wall-climbing robot based on electrically controlled permanent magnet technology is proposed, which realizes the function of magnetization and demagnetization by changing the pulse current. Between the magnetic pole unit and the magnetic workpiece, the magnetic attraction force approaches $800 \mathrm{~N}$. The ship's outer surface has a sufficient amount of magnetizing force. The magnetic attraction force is similar to $0 \mathrm{~N}$ during demagnetization, indicating that the system is fully unloaded, as predicted by the theoretical analysis. Electrically controlled permanent magnet technology addresses the contradiction between the maneuverability and the adsorption force of the wall-climbing robot. Compared with electromagnetic adsorption devices, electronically controlled permanent magnet technology presents no safety hazards due to accidental power failure or loss of adsorption. The pulse current, demagnetization time, and residual magnetism can all be adjusted in the later study to ensure the wall-climbing robot's maneuverability and adsorption force on the ship's surface.

\section{Declaration of competing interest}

The authors declared that they have no conflicts of interest to this work. We declare that we do not have any commercial or associative interest that represents a conflict of interest in connection with the work submitted.

\section{Acknowledgments}

The work was financially supported by the key marine science and technology projects of Zhoushan Science and Technology Bureau (2019C21009).

\section{References}

[1] Huang, H., Li, D., Xue, Z., Chen, X., Liu, S., Leng, J., \& Wei, Y.. Design and performance analysis of a tracked wall-climbing robot for ship inspection in shipbuilding.Ocean Engineering, 131, 224-230, 2017.

[2] Kermorgant, O. A magnetic climbing robot to perform autonomous welding in the shipbuilding industry. Robotics and Computer-Integrated Manufacturing, 53, 178-186, 2018.

[3] Jamali, S. S., \& Mills, D. J. Steel surface preparation prior to painting and its impact on protective performance of organic coating. Progress in Organic Coatings, 77(12), 2091-2099, 2014.

ISSN: 0010-8189 
[4] Yuping, L., Zhengyao, Y., Yan, L., Zhuoshang, J., Xiaoning, J., Fei, P., \& Bing, L. (2017, December). The basic functional design of wall climbing robot for hull plate spraying in dock. In 2017 2nd International Conference on Robotics and Automation Engineering (ICRAE) (pp. 89-93). IEEE. 2017.

[5] ZHANG, B. Q., ZHU, R. J., YANG, J. M., \& ZHANG, G. Y. Study on the Capacity of the Composited Adsorption on Climbing Robot. Machinery Design \& Manufacture, (8), 67, 2016.

[6] Yan, C., Sun, Z., Zhang, W., \& Chen, Q. Design of novel multidirectional magnetized permanent magnetic adsorption device for wall-climbing robots. International Journal of Precision Engineering and Manufacturing, 17(7), 871-878, 2016.

[7] Lai, X., Peng, T., \& Zhou, J. Study on variable magnetic adsorption performance of wheeled mobile wall climbing robot. International Core Journal of Engineering, 5(10), 74-80, 2019.

[8] Gao, F., Fan, J., Zhang, L., Jiang, J., \& He, S. Magnetic crawler climbing detection robot basing on metal magnetic memory testing technology. Robotics and Autonomous Systems, 125, 103439, 2020.

[9] CHEN, X. L., JIN, Z. L., LIAO, S. W., \& HE, K. Design of a Vacuum Adsorption Wall Climbing Robot. DEStech Transactions on Engineering and Technology Research, (amee), 2019.

[10] Chen, R., Fu, L., Qiu, Y., Song, R., \& Jin, Y. A gecko-inspired wall-climbing robot based on vibration suction mechanism. Proceedings of the Institution of Mechanical Engineers, Part C: Journal of Mechanical Engineering Science, 233(19-20), 7132-7143, 2019.

[11] Shao, L., Xing, Y., Li, J., Liu, H., \& Chen, X. (2018, June). Adsorption structure analysis of photovoltaic cleaning robot based on negative pressure adsorption. In 2018 Chinese Control and Decision Conference (CCDC) (pp. 4133-4137). IEEE, 2018.

[12] Tang, D. Recent Patents on Wall Climbing Robot with Negative Pressure Adsorption. Recent Patents on Engineering, 13(3), 201-211, 2019.

[13] Sano, S., Ohara, K., Ashizawa, S., Ichikawa, A., Suzuki, S., Omichi, T., \& Fukuda, T. (2017, December). Development of wall climbing robot using passive joint and vacuum pad on rough surface. In 2017 International Symposium on Micro-Nano Mechatronics and Human Science (MHS) (pp. 1-3). IEEE, 2017.

[14] Mao, J., He, K., Li, J., \& Sun, X. (2016, August). Simulation and experimental verification of permanent magnet adsorption unit for wall-climbing robot. In 2016 IEEE International Conference on Information and Automation (ICIA) (pp. 1189-1194). IEEE, 2016.

[15] Park, S. H., Seo, K. J., \& Kim, S. G. Development of wall climbing robot using vacuum adsorption with legged type movement. Journal of the Korea Academia-Industrial Cooperation Society, 18(8), 344-349, 2017.

[16] Zhou, Q., \& Li, X. (2016, October). Design of wall-climbing robot using electrically activated rotational-flow adsorption unit. In 2016 IEEE/RSJ International Conference on Intelligent Robots and Systems (IROS) (pp. 5758-5763). IEEE, 2016.

[17] Zhou, Q., \& Li, X. Experimental investigation on climbing robot using rotation-flow adsorption unit. Robotics and Autonomous Systems, 105, 112-120, 2018.

[18] Liu, J., Xu, L., Chen, S., Xu, H., Cheng, G., \& Xu, J. Development of a Bio-inspired Wall-Climbing Robot Composed of Spine Wheels, Adhesive Belts and Eddy Suction Cup. Robotica, 1-20, 2020.

[19] Li, X., Zhixiang, Z., \& Lan, Q. (2016, November). Research on a wall climbing robot based on electrostatic adhesion. In 2016 10th International Conference on Sensing Technology (ICST) (pp. 1-6). IEEE, 2016.

[20] Zhang, W., Zhang, W., \& Sun, Z. (2019, July). A Modular Soft Wall-Climbing Robot Using Electromagnetic Actuator. In 2019 IEEE 9th Annual International Conference on CYBER Technology in Automation, Control, and Intelligent Systems (CYBER) (pp. 730-733). IEEE, 2019.

[21] Zhang, Q., Xue, K., \& Luo, Y. Structure design and research of magnetic attraction wall climbing robot. International Core Journal of Engineering, 6(4), 218-224, 2020.

[22] Liu, J., Xie, L., \& Chen, X. Permanent magnetic climbing robot design and calculation of adsorption.

[23] Liu, J., Tang, D., Xie, L., \& Chen, X. Permanent magnetic climbing robot based on ANSYS gap-type 
adsorption analysis.

[24] Ming-lei, L. I., Yu-lian, Z. H. A. N. G., Xin, C. H. E. N., \& Shi-fei, W. U. (2021, February). Design and analysis of the variable-axis structure before and after the large magnetic block of the charging and discharging magnetic adsorption robot. In Journal of Physics: Conference Series (Vol. 1754, No. 1, p. 012178). IOP Publishing. 